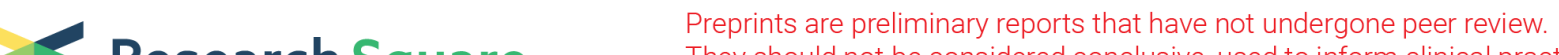 Research Square They should not be considered conclusive, used to inform clinical practice, or referenced by the media as validated information.
}

\section{Prognostic function of platelet-to-lymphocyte ratio in gynecologic cancers: A systematic review and meta-analysis}

\section{Chong Fan}

Nanjing Maternity and Child Health Care Hospital

\section{Youjin Dai}

Nanjing Medical University

\section{Yiquan Wang}

Shanghai University of Traditional Chinese Medicine

\section{Miao Miao}

Nanjing Maternity and Child Health Care Hospital

\section{Can Rui}

Nanjing Maternity and Child Health Care Hospital

\section{Xinyan Wang}

Nanjing Maternity and Child Health Care Hospital

Yu Liu

Nanjing Maternity and Child Health Care Hospital

\section{Ting Luan}

Nanjing Maternity and Child Health Care Hospital

\section{Ping Li}

Nanjing Maternity and Child Health Care Hospital

Xin Zeng ( $\square$ august555482@126.com )

\section{Research article}

\section{Keywords:}

Posted Date: December 11th, 2019

DOl: https://doi.org/10.21203/rs.2.18704/v1

License: (c) (i) This work is licensed under a Creative Commons Attribution 4.0 International License. Read Full License 


\section{Abstract}

Background: Although along with the diagnosis and treatment level enhanced, current situation of the gynecologic malignancies improved, the risk of gynecologic tumor remains high. Nowadays, inflammatory markers increasingly employed as a tumor predictive factor. Herein, we focused on the association between the platelet-to-lymphocyte ratio (PLR) and gynecological cancers, including cervical, ovarian, and endometrial cancer. Methods: In this meta-analysis, we searched systematically on the EMBASE and PubMed databases from June 1, 1989 to May 31, 2019. After excluded some unqualified articles, we calculated the pooled hazard ratio (HR) with $95 \%$ confidence interval (Cl) mainly to detect the relationship between PLR and prognostic survival, including overall survival (OS) and progression-free survival (PFS). Random-effect model was adopted when I $2>50 \%$ after Higgins I 2 test. Subgroup analysis and funnel plot were used to seek for the possible source of heterogeneity and publication bias, respectively. All statistical tests were two-sided. Results: After a series of searching and selection, twentyeight literatures containing 8290 participants totally. Among those recruited trials, 26 studies comprising 8109 patients reported HR for OS and 15 researches enrolled 4283 patients for PFS. Overall, a high value of PLR means a worse OS and PFS in women with gynecologic cancer except those with endometrial cancer for OS (pooled HR $=1.35,95 \% \mathrm{Cl}=0.73$ to $2.53, \mathrm{P}=0.33$ ). Subgroup analyses indicated that the source of heterogeneity may be primarily from the sample size, PLR cut-off, study location, published year, and the cut-off year for the study. Publication bias manifested that bias was not evident. Conclusion: Elevated pretreatment PLR portends a poor prognosis among patients with gynecological tumor, as well as in women with cervical and ovarian malignancies for both OS and PFS. However, in patients with endometrial cancer, this connection is broken for OS but still available for PFS.

\section{Background}

Although a great deal of modern therapeutic methods have been expanded for gynecologic cancer, including cervical cancer, ovarian cancer, and endometrial cancer, the estimated deaths are still high last year as before, only after lung, stomach, and liver cancer[1]. Meanwhile, with an estimated over 1,250,000 new gynecological cancer cases in 2018 worldwide[1]. These cancers can result in weight loss, abdominal pain or distension, increased abdominal size, urinary tract symptoms, and subsequently mental discomfort and economic burden[2-6], affecting patient's life quality severely. However, symptoms of these cancers are not obvious in its early stage lead to the early diagnosis rate remains low, while advanced cancer is hard to manage. In addition, current screening methods for gynecological tumors are neither costly nor actual. For ovarian cancer, bimanual pelvic examination and transvaginal ultrasound are short of enough specificity and sensitivity, and the image examination costs are enormous $[2,6]$. At the meantime, radioimmunoassay for cancer antigen 125 (CA125) only rises in $50 \%$ patients with ovarian cancer[6]. As regards endometrial cancer, clinical examination and ultrasound annually may miss the possible lesions, and the acceptability to women of endometrial biopsy remains in doubt[4]. With respect to cervical cancer, the dominant screening approaches are Papanicolaou (Pap) smear and cervical cytology in the past 60 years, but the same question, limited specificity and sensitivity, 
appears[7]. Therefore, seeking for the newly satisfied predictive factors with economical and convenient benefits are warranted.

In the past few decades, systemic inflammation has gradually been associated with cancer pathogenesis and thought as a hallmark of cancer[8-11]. Systemic inflammation usually involves in changes in neutrophil, eosinophil, platelet, lymphocyte, and other peripheral blood cell count[10, 12$]$. In tumor ambient environment, the cancer cells could recruit inflammatory cells like platelets and lymphocytes[13]. Meanwhile, some researchers have revealed that platelet deposition selectively enhance lymphocyte adhesion in the case of arterial blood flow[14], while the majority of tumor tissues are rich in blood vessel. Thus, it is undoubtedly imperative to explore the potential correlations between the inflammatory associated blood bio-markers with gynecological cancer.

Previous studies have manifested platelet-to-lymphocyte ratio (PLR) can be widely used as a prognostic marker for diverse cancers[15-18]. In these literatures, authors demonstrated that a higher level of preoperative PLR was an indicator of poor survival of different cancers, as well as in most survey results of gynecological cancers. Yet, consequence from Prachratana Nuchpramool and Jitti Hanprasertpong illustrated that PLR could not be applied as a prognostic biomarker in early-stage cervical cancer after receiving primary treatment of radical hysterectomy with pelvic lymph node dissection[19]. Because of lacking the firm uniformity in the field, making the mentioned association above clear is crucial.

In this study, we accomplished a systematic review and meta-analysis to explore the conclusive connection between the PLR and the prognosis, including overall survival (OS) and progression-free survival (PFS), of patients with ovarian, cervical, or endometrial malignancies.

\section{Methods}

\subsection{Search strategy}

A computerized search of EMBASE and PubMed databases was performed for our research. We searched for $\mathrm{MeSH}$ terms and keywords in title and abstract and the main search terms were as follows: gynecology, gynecological, cervical, cervix, ovarian, ovary, endometrial, platelet lymphocyte. We included all publications between June 1, 1989 and May 31, 2019.

\subsection{Study selection}

Articles were eligible for inclusion if they met the following criteria: (1) patients diagnosed with cervical, ovarian or endometrial cancer; (2) provided pre-treatment PLR and cut-off values; (3) studies that reported the hazard ratio (HR) and corresponding 95\% confidence interval (Cl) for overall survival (OS) and/or progression-free survival (PFS), the $\mathrm{HR}$ and $95 \% \mathrm{Cl}$ to be calculated via univariate or multivariate analysis. The exclusion criteria were as follows: (1) review articles, guidelines, letters, case reports and 
conference proceedings; (2) non-English language publication; (3) title and/or abstract only and no full text provided; (4) only relevant graphic data but not numerical value for HR provided; (5) had no identified gynecologic tumor type.

The literature search and study selection process were conducted by three authors independently. Disagreements between three authors were consulted until a consensus was reached.

\subsection{Data extraction}

Three reviewers independently extracted the detailed information using predetermined forms from the included studies with disagreements discussed until consensus finished. For each study, we extracted characteristics on first author, year of publication, research location, study duration, number of available patients, median or mean age and age range of participants, stage and grade of diverse cancer, histopathologic subtype of tumor, lymph node metastasis whether or not, treatment methods, median or mean follow-up time. OS, PFS, as well as its HR with associated $95 \% \mathrm{Cl}$, were also be recorded.

\subsection{Statistical analysis}

Extracted data from the enrolled studies were analyzed using RevMan 5.3 software (Cochrane Collaboration, Copenhagen, Denmark). Survival outcomes, both OS and PFS included, were the primary interests in this meta-analysis. Therefore, the Log (HR) and standard error were calculated according to HRs and their $95 \%$ confidence intervals. Heterogeneity was evaluated via Cochran's Q test and the Higgins $\mathrm{I}^{2}$ statistic. While $\mathrm{P}<0.05$ was calculated by Cochran's $\mathrm{Q}$ test, heterogeneity between literatures was manifested. In the Higgins $\mathrm{I}^{2}$ test, the value of $\mathrm{I}^{2}$ could considered as a criterion to estimate the degree of heterogeneity and the reference standards were as follows: if $\mathrm{I}^{2}$ no more than $40 \%$, heterogeneity could be negligible; if $\mathrm{I}^{2}$ between $30 \%$ and $60 \%$, moderate heterogeneity might be shown; while $\mathrm{I}^{2}$ falls into $50-90 \%$, evident heterogeneity may be presented; when $\mathrm{I}^{2}=75-100 \%$, inevitable heterogeneity exists[20]. Meanwhile, $I^{2}>50 \%$ in the Higgins $I^{2}$ test were termed as significant heterogeneity, and then a random effects model was chosen; or else, if $\mathrm{I}^{2}<50 \%$, a fixed effects model was performed. We also conducted subgroup analyses to detect the potential sources of heterogeneity though RevMan 5.3 software. And the items of subgroup analysis contain sample size, PLR cut-off, study location, the cut-off year for the research, published year of the articles, median age, and other subgroup that may impact the heterogeneity between the studies. In addition, funnel plots were employed for testing publication bias. Pvalues $<0.05$ was considered as statistically significant, and all adopted tests were two-sided.

\section{Results}

\subsection{Literature search results and characteristics}


The literature search results and detailed study selection steps are shown in Figure 1. The database searching yielded 556 publications originally. After removing 154 duplicates, and screening residual titles and abstracts of 402 articles, 83 articles remained. Of the remaining studies, 53 literatures were further excluded for various reasons: eight reviews, two with non-English language, thirteen provided conference summary or abstract only, thirty-one did not offered numerical value for hazard ratio, and one with only gynecologic cancer but no primary cancer. Finally, a total of 28 articles and 8290 participants were included in this review and meta-analysis. Among them, one concerning cervical cancer was disposed separately cause of providing HRs and survival outcomes for patients with two different treatments[21]. As a consequence, fifteen, nine, and four publications regarding to cervical[19, 21-34], ovarian[35-43], and endometrial cancer[44-47] were enrolled, respectively.

Characteristics of all enrolled studies are shown in Table 1. The publication of all enrolled studies ranged from 2011 to 2019 and the duration of experiments were from 1988 to 2016. Six studies were from Europe (Spain, Poland, the United Kingdom, and Italy) and the remained twenty-two were from Asia (Korea, China, Japan, Turkey, and Thailand). The number of study population recruited in each research were ranged from 36 to 795 patients. The outcomes of all included cancer were also recorded. PLR cutoff were extracted from the above-mentioned 28 researches, too.

\subsection{Overall survival and progression-free survival}

Two forest plots of all articles for OS and PFS are displayed as Figure 2A and Figure 2B, respectively. Overall, higher PLR represents worse survival in this data, both for OS $(\mathrm{HR}=1.49,95 \% \mathrm{Cl}=1.23-1.82)$ and PFS ( $\mathrm{HR}=1.63,95 \% \mathrm{Cl}=1.30-2.05)$. Among all included studies, twenty-six studies consisting of 8109 participants reported HR for OS. In the meantime, for PFS, fifteen of the eligible twenty-eight literatures comprising 4283 patients. Thereinto, seven articles reported HR from univariate analysis for OS or PFS and the remained twenty-one were from multivariate analysis. The patients had a median age (age range $=18$ to 95) from 44 to 63 years old in twenty-four studies which reported the median age. The median cutoff for PLR was 169 (range =138.35 to 300) for OS, while it was 172.50 (range =62.31 to 300) for PFS. Relevant follow-up information (duration of median or mean follow-up) were recorded in nineteen researches, ranged from 0.1 to 175.3 months. A random-effects model was performed since the presence of heterogeneity $\left(\mathrm{I}^{2}=85 \%, \mathrm{P}<0.0001\right.$ and $\mathrm{I}^{2}=81 \%, \mathrm{P}<0.00001$ for $\mathrm{OS}$ and PFS, respectively) existed between the applicable literatures.

\subsection{Overall survival and progression-free survival by primary tumor}

The results of subgroup analysis by primary tumor are shown in Figure 3A and Figure 3B. From the Figure $3 A$ and $3 B$, our work manifested that the lower PLR represented the better prognostic except for OS with 
endometrial cancer. In patients with endometrial cancer, the HR and its $95 \% \mathrm{Cl}$ for OS was $1.35(0.73$, 2.50). But for PFS, the corresponding outcome was $1.86(1.20,2.91)$ and Higgins $I^{2}$ test declared $I^{2}=0 \%$.

\subsection{Subgroup analysis of overall survival and progression-free survival}

In the subgroup analyses, three details should be stated initially. In the subgroup of median age, one research[42] provided two different median age (60 and 63) for diverse group. However, this did not influence the classification of subgroup in this data due to the cut-off value of median age was 50 years old. Another issue worth noting was that the Turkey was identified as a European country in this data on account of their living habits and ethnics were closer to Europe but not Asia. One last thing to note is that the subgroup analysis of endometrial cancer did not be carried out because of a relatively low number of recruited literatures.

\subsubsection{Gynecologic cancer}

The results of gynecologic cancer subgroup analyses were exhibited in Table 2 and several sources of heterogeneity were found. In women with gynecological tumor, stratified analysis discovered several sources of heterogeneity and almost all heterogeneity decreased after subgroup analyses. Concerning OS, we found heterogeneity reduced in the published year (pooled $\mathrm{HR}=1.49 ; 95 \% \mathrm{Cl}=1.03$ to $1.17 ; \mathrm{P}<0.0001$ ) and median age (pooled $\mathrm{HR}=1.47 ; 95 \% \mathrm{Cl}=1.18$ to $1.82 ; \mathrm{P}=0.0005$ ) subgroup in all 26 eligible literatures containing 27 different trials. However, as for PFS, despite the heterogeneity equally shortened in the subgroup of the published year (pooled HR $=1.63 ; 95 \% \mathrm{Cl}=1.30$ to $2.05 ; \mathrm{P}<0.0001$ ), heterogeneity switched softly in the median age (pooled $\mathrm{HR}=1.58 ; 95 \% \mathrm{Cl}=1.22$ to $2.06 ; \mathrm{P}=0.0006$ ) stratified group in all 16 trials. Among other subgroup analyses, including PLR cut-off, study location, the cut-off year for the study, and sample size subgroup, significant pooled HR and lessened heterogeneity were also observed visibly for PFS but not so remarkable for OS. Regarding study location, we did further classification and found that $\mathrm{I}^{2}$ dropped to $0 \%$ after Higgins $\mathrm{I}^{2}$ test in women who suffered from ovarian cancer and endometrial cancer despite the elevation in the cases with cervical cancer in Asian. With respect to OS, whether it was in Asia or Europe, we failed to explore the exact origin of the heterogeneity even heterogeneity declined to some degree but far from enough.

\subsubsection{Cervical cancer}

The analytical consequences of cervical cancer were presented in Table 3 and supplement 1. Four subgroups were designed to search the underlying sources of heterogeneity for OS but three for PFS and matching trials were fifteen and eight, respectively. Similar to overall analysis for OS above, the cut-off year for the study (pooled $\mathrm{HR}=1.48 ; 95 \% \mathrm{Cl}=1.08$ to $2.04 ; \mathrm{P}=0.02$ ) and published year subgroup 
analytical results displayed the significant heterogeneity reduction in one of the layered groups, whereas in the sample size and the PLR cut-off subgroup the decline did not illustrate significant heterogeneity. For PFS, after three subgroup analyses, opposite change occurred between groups of one subgroup: heterogeneity descended in the groups with sample size $\leq 200$ patients, the cut-off year for the study from 2009 to 2012, and published year between 2011 and 2016, but conversely added in the other group.

\subsubsection{Ovarian cancer}

The corresponding results of ovarian cancer were diplayed in Table 3 and supplement 1 . Still four and three subgroups were exploited for heterogeneity analyses for OS and PFS. Heterogeneity of the stratified group of published year (pooled HR =1.51; 95\% Cl =1.16 to 1.96; $\mathrm{P}<0.002$ ) from 2011 to 2016 illustrated a shrinkage as before, as well as sample size in spite of group altered. In regard to PFS, several favorable survival results were recognized about ovarian cancer and resembled to women with cervical cancer.

\subsection{Publication bias analysis}

From funnel plot (Figure 4A \& 4B), our results suggested that publication bias was low for both OS and PFS.

\section{Discussion}

Accumulating evidence implies that inflammation acts an absolutely required part in the formation of neoplasm possibly via all kinds of transcription factors, chemokines, as well as cytokines[10, 11]. In many published knowledges, the roles of inflammatory factors like neutrophil-to-lymphocyte ratio (NLR) [48], monocyte-to-lymphocyte ratio (MLR)[49], and C-reactive protein (CRP)[50] have always been delineated in patients who suffered from cancer. Given that, we turned our attention on the association between another inflammatory immune factors, platelet-to-lymphocyte ratio (PLR), and gynecological cancer.

According to the present review and meta-analysis, we evaluated the prognostic effects of PLR for ovarian, cervical, and endometrial cancers and ultimately found that an elevated PLR was linked to both shorter OS and poorer PFS in the ovarian cancer and cervical cancer, in keeping with many known outcomes with several other sorts of neoplasm such as early stage classical Hodgkin lymphoma[51], hepatopancreatico-biliary malignancy[52], early stage non-small-cell lung cancer[15], gastric cancer[16], breast cancer[17], and esophageal cancer[18]. But contrary result appeared in endometrial cancer, 
pretreatment low or high value of PLR had no impact on OS in endometrial tumor, while higher value of PLR denoted inferior PFS.

After subgroup analyses, we detect some meaningful outcomes likewise. Nearly in all published year subgroups, decreased heterogeneity in stratified group (2011 2016) was observed and P value for all pooled HR in the subgroup for diverse analyses were less than 0.05 . Hence, we have adequate reasons to believe that heterogeneity between literatures may come from those which are published later than 2016. Comparably, in the majority of the cut-off year for the study subgroups, our consequences revealed that the relatively later cut-off year for the study, the higher heterogeneity happened to the studies we included these observations. Combined to the published year subgroup analysis, we speculated that the latest researches could exist certain inconsistence since the later the trial stopped, the more recent the study published. And this may be resulted from the rapid medical development particularly in cancer evolution[53] and along with the new controversy appeared, as well as the incompatible evaluation criterion. For this account, inclusion criteria for patients may various and enrolled women with tumor and treatment methods differ followed would have an inherent impact on the outcomes. Additionally, sample size no more than 200 could be taken as another source of the heterogeneity both in cervical and ovarian cancer. Moreover, study location may constitute another sources of heterogeneity for PFS. Heterogeneity was relatively low in Asian patients, especially for endometrial cancer. But this may not make sense because of the few literatures included in our report. Regretfully, for OS, maybe due to the large amount of the studies, we do not ensure sufficient resources of heterogeneity in women with gynecologic tumor.

To our knowledge, this study firstly summarizes the potential prognostic for PLR on overall gynecologic cancer patients, as well as cervical cancer, ovarian cancer, and endometrial cancer. Further, we detected the underlying sources of heterogeneity, and possible causes displayed subsequently. In addition, we recruited the ample researches in the present report. Despite the heavy workload, we furnished the convincing proof, which could offer a reference for clinical management with gynecologic cancer patients.

Some limitations still inevitably exist in this study. First, almost all of the contained observations in this data were retrospective but not prospective cohort study, which may lead to bias in data processing. At the same time, because significant results were easier to be accepted by journal now, the role of PLR may be overestimated virtually. Besides, available data extracted from the above-mentioned articles were gathered instead of specific personal information also further exaggerated the potential bias. Second, PLR was susceptible to influence via other diseases not only gynecological cancer. For example, several authors had reported chronic hepatitis B virus infection[54], Helicobacter pylori infection[55], acute kidney injury[56] all had an impact on the value of PLR. But many selected studies did not eliminate such corresponding conditions in our work and subsequently imbalance between groups came. Therefore, PLR cannot be used as an independent judgment prognostic indicator, but can be applied as an auxiliary indicator. Third, the other inconformity between the literatures were that not all researches adopted the multivariate model. Nearly a quarter researches used the univariate model to explore the correlation between the PLR and gynecologic cancer. Meanwhile, not all results from the recruited studies were 
statistically significant. Moreover, different therapeutic methods for gynecologic cancer could have influence on the observed index, but this is hard to manage.

\section{Conclusions}

In conclusion, our currently results manifest that a higher value of pretreatment PLR indicates a worse prognosis among patients with gynecologic malignancies, as well as in patients with cervical, ovarian, and endometrial cancer for both OS and PFS except in those with endometrial cancer for OS. This provides us a therapeutic thought of that we could improve the prognosis of gynecological cancers by reducing the value of PLR, that is to say, attenuating the platelet count within certain range correspondingly should be considered. Though PLR do not set up as an independent prognostic indicator, it can help clinicians judge the prognosis of gynecologic cancer. But for all that, more perspective investigations need to be performed and the appropriate cut-off for PLR remains to be determined in the near future.

\section{Abbreviations}

PLR囚platelet-to-lymphocyte ratio; HR: hazard ratio; Cl: confidence interval; OS: overall survival; PFS: progression-free survival; CA125: cancer antigen 125; NLR: neutrophil-to-lymphocyte ratio; MLR: monocyte-to-lymphocyte ratio; CRP: C-reactive protein.

\section{Declarations}

\section{Ethics approval and consent to participate}

Not applicable.

\section{Consent for publication}

Not applicable.

\section{Availability of data and materials}

The datasets generated and/or analyzed during the current study are available from the corresponding author on reasonable request. 


\section{Competing interests}

The authors declare that they have no competing interests.

\section{Funding}

This work was supported by the National Natural Science Foundation of China (no. 81671410, 81871474 and 81801480), Nanjing medical science and technique development foundation (no. QRX17072).

\section{Authors' contributions}

LP and ZX obtained funding for the study and conceptualized and designed the study. FC, DYJ, WYQ, MM and RC collected the data. FC, DYJ and WYQ screened and extracted the data. MM and RC conducted data analysis. WXY, LY, and LT reviewed the data analysis. FC drafted the article. DYJ, WYQ, LP and ZX critically revised the article. All authors have read and approved the final article.

\section{Acknowledgments}

Not applicable.

\section{Author details}

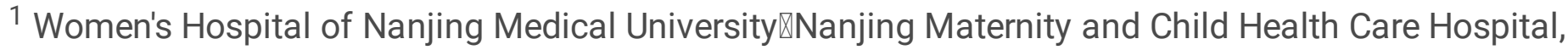
Nanjing, Jiangsu 210004, China. ${ }^{2}$ Key Laboratory of Model Animal Research, Animal Core Facility of Nanjing Medical University, Nanjing Medical University, 101 Longmian Avenue, Nanjing, Jiangsu 211166, China. ${ }^{3}$ Department of Internal Medicine, Longhua Hospital affiliated to Shanghai University of Traditional Chinese Medicine, Shanghai 200032, China.

\section{References}

[1] Bray F, Ferlay J, Soerjomataram I, Siegel RL, Torre LA, Jemal A. Global cancer statistics 2018: GLOBOCAN estimates of incidence and mortality worldwide for 36 cancers in 185 countries. CA: A Cancer Journal for Clinicians. 2018;68:394-424.

[2] Jayson GC, Kohn EC, Kitchener HC, Ledermann JA. Ovarian cancer. The Lancet. 2014;384:1376-88. 
[3] Goff BA, Mandel LS, Melancon CH, Muntz HG. Frequency of Symptoms of Ovarian Cancer in Women Presenting to Primary Care Clinics. JAMA. 2004;291:2705-12.

[4] Morice P, Leary A, Creutzberg C, Abu-Rustum N, Darai E. Endometrial cancer. The Lancet. 2016;387:1094-108.

[5] Cohen PA, Jhingran A, Oaknin A, Denny L. Cervical cancer. The Lancet. 2019;393:169-82.

[6] Jelovac $D$, Armstrong DK. Recent progress in the diagnosis and treatment of ovarian cancer. $C A$ Cancer J Clin. 2011;61:183-203.

[7] Goodman A. HPV testing as a screen for cervical cancer. BMJ (Clinical research ed). 2015;350:h2372h.

[8] Hanahan D, Weinberg RA. Hallmarks of cancer: the next generation. Cell. 2011;144:646-74.

[9] Elinav E, Nowarski R, Thaiss CA, Hu B, Jin C, Flavell RA. Inflammation-induced cancer: crosstalk between tumours, immune cells and microorganisms. Nat Rev Cancer. 2013;13:759-71.

[10] Mantovani A, Allavena P, Sica A, Balkwill F. Cancer-related inflammation. Nature. 2008;454:436-44.

[11] Diakos $\mathrm{Cl}$, Charles KA, McMillan DC, Clarke SJ. Cancer-related inflammation and treatment effectiveness. The Lancet Oncology. 2014;15:e493-e503.

[12] Jenne CN, Kubes P. Platelets in inflammation and infection. Platelets. 2015;26:286-92.

[13] Chen X, Wang Q, Liu L, Sun T, Zhou W, Chen Q, et al. Double-sided effect of tumor microenvironment on platelets targeting nanoparticles. Biomaterials. 2018;183:258-67.

[14] Spectre G, Zhu L, Ersoy M, Hjemdahl P, Savion N, Varon D, et al. Platelets selectively enhance lymphocyte adhesion on subendothelial matrix under arterial flow conditions. Thromb Haemost. 2012;108:328-37.

[15] Cannon NA, Meyer J, lyengar P, Ahn C, Westover KD, Choy H, et al. Neutrophil-lymphocyte and plateletlymphocyte ratios as prognostic factors after stereotactic radiation therapy for early-stage non-small-cell lung cancer. J Thorac Oncol. 2015;10:280-5.

[16] Chen XD, Mao CC, Wu RS, Zhang WT, Lin J, Sun XW, et al. Use of the combination of the preoperative platelet-to-lymphocyte ratio and tumor characteristics to predict peritoneal metastasis in patients with gastric cancer. PLoS One. 2017;12:e0175074.

[17] Liu C, Huang Z, Wang Q, Sun B, Ding L, Meng X, et al. Usefulness of neutrophil-to-lymphocyte ratio and platelet-to-lymphocyte ratio in hormone-receptor-negative breast cancer. Onco Targets Ther. 2016;9:4653-60. 
[18] McLaren PJ, Bronson NW, Hart KD, Vaccaro GM, Gatter KM, Thomas CR, Jr., et al. Neutrophil-toLymphocyte and Platelet-to-Lymphocyte Ratios can Predict Treatment Response to Neoadjuvant Therapy in Esophageal Cancer. J Gastrointest Surg. 2017;21:607-13.

[19] Nuchpramool P, Hanprasertpong J. Preoperative Neutrophil-Lymphocyte Ratio and PlateletLymphocyte Ratio Are Not Clinically Useful in Predicting Prognosis in Early Stage Cervical Cancer. Surgery research and practice. 2018;2018:9162921.

[20] Woo S, Suh CH, Kim SY, Cho JY, Kim SH. Diagnostic Performance of Magnetic Resonance Imaging for the Detection of Bone Metastasis in Prostate Cancer: A Systematic Review and Meta-analysis. Eur Urol. 2018;73:81-91.

[21] Haraga J, Nakamura K, Omichi C, Nishida T, Haruma T, Kusumoto T, et al. Pretreatment prognostic nutritional index is a significant predictor of prognosis in patients with cervical cancer treated with concurrent chemoradiotherapy. Molecular and clinical oncology. 2016;5:567-74.

[22] Lee JW, Jeon S, Mun ST, Lee SM. Prognostic Value of Fluorine-18 Fluorodeoxyglucose Uptake of Bone Marrow on Positron Emission Tomography/Computed Tomography for Prediction of Disease Progression in Cervical Cancer. International journal of gynecological cancer : official journal of the International Gynecological Cancer Society. 2017;27:776-83.

[23] He X, Li JP, Liu XH, Zhang JP, Zeng QY, Chen H, et al. Prognostic value of C-reactive protein/albumin ratio in predicting overall survival of Chinese cervical cancer patients overall survival: comparison among various inflammation based factors. Journal of Cancer. 2018;9:1877-84.

[24] Nakamura K, Nakayama K, Tatsumi N, Minamoto T, Ishibashi T, Ohnishi K, et al. Prognostic significance of pre-treatment neutrophil-to-lymphocyte and platelet-to-lymphocyte ratios in non-surgically treated uterine cervical carcinoma. Molecular and clinical oncology. 2018;9:138-44.

[25] Onal C, Guler OC, Yildirim BA. Prognostic Use of Pretreatment Hematologic Parameters in Patients Receiving Definitive Chemoradiotherapy for Cervical Cancer. International journal of gynecological cancer : official journal of the International Gynecological Cancer Society. 2016;26:1169-75.

[26] Zheng RR, Huang M, Jin C, Wang HC, Yu JT, Zeng LC, et al. Cervical cancer systemic inflammation score: a novel predictor of prognosis. Oncotarget. 2016;7:15230-42.

[27] Huang H, Liu Q, Zhu L, Zhang Y, Lu X, Wu Y, et al. Prognostic Value of Preoperative Systemic ImmuneInflammation Index in Patients with Cervical Cancer. Sci Rep. 2019;9:3284.

[28] Holub K, Biete A. Impact of systemic inflammation biomarkers on the survival outcomes of cervical cancer patients. Clinical \& translational oncology : official publication of the Federation of Spanish Oncology Societies and of the National Cancer Institute of Mexico. 2019;21:836-44. 
[29] Wang L, Jia J, Lin L, Guo J, Ye X, Zheng X, et al. Predictive value of hematological markers of systemic inflammation for managing cervical cancer. Oncotarget. 2017;8:44824-32.

[30] Zhang W, Liu K, Ye B, Liang W, Ren Y. Pretreatment C-reactive protein/albumin ratio is associated with poor survival in patients with stage IB-IIA cervical cancer. Cancer medicine. 2018;7:105-13.

[31] Jonska-Gmyrek J, Gmyrek L, Zolciak-Siwinska A, Kowalska M, Fuksiewicz M, Kotowicz B. Pretreatment neutrophil to lymphocyte and platelet to lymphocyte ratios as predictive factors for the survival of cervical adenocarcinoma patients. Cancer management and research. 2018;10:6029-38.

[32] Zhu M, Feng M, He F, Han B, Ma K, Zeng X, et al. Pretreatment neutrophil-lymphocyte and plateletlymphocyte ratio predict clinical outcome and prognosis for cervical Cancer. Clinica chimica acta; international journal of clinical chemistry. 2018;483:296-302.

[33] Chen L, Zhang F, Sheng XG, Zhang SQ, Chen YT, Liu BW. Peripheral platelet/lymphocyte ratio predicts lymph node metastasis and acts as a superior prognostic factor for cervical cancer when combined with neutrophil: Lymphocyte. Medicine. 2016;95:e4381.

[34] Ida N, Nakamura K, Saijo M, Kusumoto T, Masuyama H. Prognostic nutritional index as a predictor of survival in patients with recurrent cervical cancer. Molecular and clinical oncology. 2018;8:257-63.

[35] Miao Y, Yan Q, Li S, Li B, Feng Y. Neutrophil to lymphocyte ratio and platelet to lymphocyte ratio are predictive of chemotherapeutic response and prognosis in epithelial ovarian cancer patients treated with platinum-based chemotherapy. Cancer biomarkers : section A of Disease markers. 2016;17:33-40.

[36] Raungkaewmanee S, Tangjitgamol S, Manusirivithaya S, Srijaipracharoen S, Thavaramara T. Platelet to lymphocyte ratio as a prognostic factor for epithelial ovarian cancer. Journal of gynecologic oncology. 2012;23:265-73.

[37] Badora-Rybicka A, Nowara E, Starzyczny-Slota D. Neutrophil-to-lymphocyte ratio and platelet-tolymphocyte ratio before chemotherapy as potential prognostic factors in patients with newly diagnosed epithelial ovarian cancer. ESMO open. 2016;1:e000039.

[38] Liu Y, Chen S, Zheng C, Ding M, Zhang L, Wang L, et al. The prognostic value of the preoperative creactive protein/albumin ratio in ovarian cancer. BMC cancer. 2017;17:285.

[39] Supoken A, Kleebkaow P, Chumworathayi B, Luanratanakorn S, Kietpeerakool C. Elevated preoperative platelet to lymphocyte ratio associated with decreased survival of women with ovarian clear cell carcinoma. Asian Pacific journal of cancer prevention : APJCP. 2014;15:10831-6.

[40] Asher V, Lee J, Innamaa A, Bali A. Preoperative platelet lymphocyte ratio as an independent prognostic marker in ovarian cancer. Clinical \& translational oncology : official publication of the Federation of Spanish Oncology Societies and of the National Cancer Institute of Mexico. 2011;13:499503. 
[41] Li Z, Hong N, Robertson M, Wang C, Jiang G. Preoperative red cell distribution width and neutrophilto-lymphocyte ratio predict survival in patients with epithelial ovarian cancer. Sci Rep. 2017;7:43001.

[42] Farolfi A, Petrone M, Scarpi E, Galla V, Greco F, Casanova C, et al. Inflammatory Indexes as Prognostic and Predictive Factors in Ovarian Cancer Treated with Chemotherapy Alone or Together with Bevacizumab. A Multicenter, Retrospective Analysis by the MITO Group (MITO 24). Targeted oncology. 2018;13:469-79.

[43] Zhang WW, Liu KJ, Hu GL, Liang WJ. Preoperative platelet/lymphocyte ratio is a superior prognostic factor compared to other systemic inflammatory response markers in ovarian cancer patients. Tumour biology : the journal of the International Society for Oncodevelopmental Biology and Medicine. 2015;36:8831-7.

[44] Cummings M, Merone L, Keeble C, Burland L, Grzelinski M, Sutton K, et al. Preoperative neutrophil:lymphocyte and platelet:lymphocyte ratios predict endometrial cancer survival. British journal of cancer. 2015;113:311-20.

[45] Aoyama T, Takano M, Miyamoto M, Yoshikawa T, Kato K, Sakamoto T, et al. Pretreatment Neutrophilto-Lymphocyte Ratio Was a Predictor of Lymph Node Metastasis in Endometrial Cancer Patients. Oncology. 2019;96:259-67.

[46] Haruma T, Nakamura K, Nishida T, Ogawa C, Kusumoto T, Seki N, et al. Pre-treatment neutrophil to lymphocyte ratio is a predictor of prognosis in endometrial cancer. Anticancer Res. 2015;35:337-43.

[47] Li J, Lin J, Luo Y, Kuang M, Liu Y. Multivariate Analysis of Prognostic Biomarkers in Surgically Treated Endometrial Cancer. PLoS One. 2015;10:e0130640.

[48] Grenader T, Waddell T, Peckitt C, Oates J, Starling N, Cunningham D, et al. Prognostic value of neutrophil-to-lymphocyte ratio in advanced oesophago-gastric cancer: exploratory analysis of the REAL-2 trial. Ann Oncol. 2016;27:687-92.

[49] Choi YH, Lee JW, Lee SH, Choi JH, Kang J, Lee BS, et al. A High Monocyte-to-Lymphocyte Ratio Predicts Poor Prognosis in Patients with Advanced Gallbladder Cancer Receiving Chemotherapy. Cancer epidemiology, biomarkers \& prevention : a publication of the American Association for Cancer Research, cosponsored by the American Society of Preventive Oncology. 2019;28:1045-51.

[50] Koch A, Fohlin H, Sorenson S. Prognostic significance of C-reactive protein and smoking in patients with advanced non-small cell lung cancer treated with first-line palliative chemotherapy. J Thorac Oncol. 2009;4:326-32.

[51] Reddy JP, Hernandez M, Gunther JR, Dabaja BS, Martin GV, Jiang W, et al. Pre-treatment neutrophil/lymphocyte ratio and platelet/lymphocyte ratio are prognostic of progression in early stage classical Hodgkin lymphoma. British Journal of Haematology. 2018;180:545-9. 
[52] Spolverato G, Maqsood H, Kim Y, Margonis GA, Luo T, Ejaz A, et al. Neutrophil-lymphocyte and platelet-lymphocyte ratio in patients after resection for hepato-pancreatico-biliary malignancies. Journal of Surgical Oncology. 2015;111:868-74.

[53] von Loga K, Gerlinger M. Cancer (r)evolution. Nature ecology \& evolution. 2017;1:1051-2.

[54] Zhao Z, Liu J, Wang J, Xie T, Zhang Q, Feng S, et al. Platelet-to-lymphocyte ratio (PLR) and neutrophilto-lymphocyte ratio (NLR) are associated with chronic hepatitis B virus (HBV) infection. International immunopharmacology. 2017;51:1-8.

[55] Farah R, Hamza H, Khamisy-Farah R. A link between platelet to lymphocyte ratio and Helicobacter pylori infection. Journal of clinical laboratory analysis. 2018;32.

[56] Zheng C-F, Liu W-Y, Zeng F-F, Zheng M-H, Shi H-Y, Zhou Y, et al. Prognostic value of platelet-tolymphocyte ratios among critically ill patients with acute kidney injury. Critical Care. 2017;21.

\section{Tables}


Table 1.

Characteristics of recruited studies.

\begin{tabular}{|c|c|c|c|c|c|c|c|}
\hline Study & $\begin{array}{l}\text { Published } \\
\text { year }\end{array}$ & $\begin{array}{l}\text { Duration of } \\
\text { study }\end{array}$ & Country & Number & Age & Analysis & PLR cut-off \\
\hline \multicolumn{8}{|l|}{ Cervical cancer } \\
\hline Lee [22] & 2017 & $\begin{array}{l}2011.03- \\
2014.12\end{array}$ & Korea & 377 & $52(29-79)$ & PFS & 170.00 \\
\hline $\mathrm{He}[23]$ & 2018 & $\begin{array}{l}2007.09- \\
2009.03\end{array}$ & China & 229 & $44(28-79)$ & OS & 149.27 \\
\hline Nakamura [24] & 2018 & $\begin{array}{l}1997.01- \\
2013.07\end{array}$ & Japan & 98 & $65(32-86)$ & OS & 212.00 \\
\hline Onal [25] & 2016 & $\begin{array}{l}2006.10- \\
2014.09\end{array}$ & Turkey & 235 & $57(21-86)$ & $\begin{array}{l}\text { OS, } \\
\text { PFS }\end{array}$ & 133.02 \\
\hline Zheng [26] & 2016 & $\begin{array}{l}2005.05- \\
2012.12\end{array}$ & China & 795 & $49.5 \pm 10.7$ & $\begin{array}{l}\text { OS, } \\
\text { PFS }\end{array}$ & 128.30 \\
\hline Huang [27] & 2019 & $2006-2015$ & China & 328 & $45(22-86)$ & OS & 118.00 \\
\hline Holub [28] & 2018 & $\begin{array}{l}2009.06- \\
2016.07\end{array}$ & Spain & 151 & $51(25-92)$ & OS & 210.00 \\
\hline Wang [29] & 2017 & $\begin{array}{l}2012.01- \\
2014.05\end{array}$ & China & 129 & $51(25-79)$ & OS & 148.90 \\
\hline Zhang [30] & 2017 & $\begin{array}{l}2005.01- \\
2009.12\end{array}$ & China & 235 & $46(29-78)$ & $\begin{array}{l}\text { OS, } \\
\text { PFS }\end{array}$ & 176.50 \\
\hline Nuchpramool [19] & 2018 & $\begin{array}{l}2001.01- \\
2016.06\end{array}$ & Thailand & 460 & 47 & $\begin{array}{l}\text { OS, } \\
\text { PFS }\end{array}$ & 119.00 \\
\hline $\begin{array}{l}\text { Jonska-gmyrek } \\
\text { [31] }\end{array}$ & 2018 & $\begin{array}{l}2003.11- \\
2008.11\end{array}$ & Poland & 52 & $53(20-81)$ & OS & 158.00 \\
\hline Zhu [32] & 2018 & $\begin{array}{l}2012.07- \\
2014.12\end{array}$ & China & 339 & $45(21-76)$ & $\begin{array}{l}\text { OS, } \\
\text { PFS }\end{array}$ & 143.79 \\
\hline $\begin{array}{l}\text { Haraga(CCRT) } \\
\text { [21] }\end{array}$ & 2016 & $\begin{array}{l}2007.04- \\
2013.03\end{array}$ & Japan & 131 & $61.5(25-88)$ & $\begin{array}{l}\text { OS, } \\
\text { PFS }\end{array}$ & 172.50 \\
\hline $\begin{array}{l}\text { Haraga(RT alone) } \\
\text { [21] }\end{array}$ & 2016 & $\begin{array}{l}2007.04- \\
2013.03\end{array}$ & Japan & 131 & $61.5(25-88)$ & $\begin{array}{l}\text { OS, } \\
\text { PFS }\end{array}$ & 128.00 \\
\hline Chen [33] & 2016 & $\begin{array}{l}2006.01- \\
2009.12\end{array}$ & China & 407 & 44 & OS & 138.35 \\
\hline Ida [34] & 2018 & $\begin{array}{l}2004.04- \\
2015.12\end{array}$ & Japan & 79 & $52.4(25-78)$ & OS & 260.00 \\
\hline \multicolumn{8}{|l|}{ Ovarian cancer } \\
\hline Miao [35] & 2016 & $2005-2010$ & China & 344 & $55(45-84)$ & $\begin{array}{l}\text { OS, } \\
\text { PFS }\end{array}$ & 207.00 \\
\hline $\begin{array}{l}\text { Raungkaewmanee } \\
{[36]}\end{array}$ & 2012 & $\begin{array}{l}2004.01- \\
2010.12\end{array}$ & Thailand & 166 & $53(23-85)$ & $\begin{array}{l}\text { OS, } \\
\text { PFS }\end{array}$ & 200.00 \\
\hline \multirow{2}{*}{$\begin{array}{l}\text { Badora-Rybicka } \\
\text { [37] }\end{array}$} & 2017 & \multirow[t]{2}{*}{$2007-2013$} & \multirow[t]{2}{*}{ Poland } & \multirow[t]{2}{*}{315} & \multirow[t]{2}{*}{$54(22-77)$} & \multirow{2}{*}{$\begin{array}{l}\text { OS, } \\
\text { PFS }\end{array}$} & $129.78(\mathrm{OS})$ \\
\hline & & & & & & & 62.31(PFS) \\
\hline Liu [38] & 2017 & $\begin{array}{l}2006.06- \\
2012.07\end{array}$ & China & 200 & $53(18-83)$ & OS & 165.00 \\
\hline Supoken [39] & 2014 & $\begin{array}{l}2003.01- \\
2013.10\end{array}$ & Thailand & 36 & 52 & PFS & 300.00 \\
\hline Asher [40] & 2011 & 1988-1998 & The UK & 235 & $62(24-90)$ & OS & 300.00 \\
\hline Li [41] & 2017 & $2000-2010$ & China & 654 & $63(28-93)$ & OS & 273.50 \\
\hline Farolfi [42] & 2018 & $\begin{array}{l}\text { 2007.01.01- } \\
2015.06 .30\end{array}$ & Italy & 375 & $60,63(19-85)$ & $\begin{array}{l}\text { OS, } \\
\text { PFS }\end{array}$ & 169.00 \\
\hline Zhang [43] & 2015 & $\begin{array}{l}2000.01- \\
2012.12\end{array}$ & China & 190 & $\begin{array}{l}50.6 \pm 11.1(24- \\
76)\end{array}$ & $\begin{array}{l}\text { OS, } \\
\text { PFS }\end{array}$ & 203.00 \\
\hline
\end{tabular}




\begin{tabular}{|c|c|c|c|c|c|c|c|}
\hline \multicolumn{8}{|c|}{ Endometrial cancer } \\
\hline Cummings [44] & 2015 & $\begin{array}{l}2005.01- \\
2007.12\end{array}$ & The UK & 605 & $65(28-95)$ & OS & 240.00 \\
\hline Aoyama [45] & 2019 & $2007-2013$ & Japan & 197 & $59(31-85)$ & $\begin{array}{l}\text { OS, } \\
\text { PFS }\end{array}$ & 206.00 \\
\hline Haruma [46] & 2015 & $\begin{array}{l}2002.01- \\
2012.12\end{array}$ & Japan & 320 & $57.5(23-86)$ & $\begin{array}{l}\text { OS, } \\
\text { PFS }\end{array}$ & 175.72 \\
\hline Li [47] & 2015 & $\begin{array}{l}2007.09- \\
2009.06\end{array}$ & China & 282 & $53(21-76)$ & OS & 250.00 \\
\hline
\end{tabular}


Table 2.

Subgroup analyses of main outcome for gynecologic cancer

\begin{tabular}{|c|c|c|c|c|c|}
\hline \multirow[t]{2}{*}{ Subgroups } & \multirow{2}{*}{$\begin{array}{l}\text { No. of } \\
\text { studies }\end{array}$} & \multirow[t]{2}{*}{ HR $(95 \%$ CI) } & \multirow[t]{2}{*}{$P$ value } & \multicolumn{2}{|c|}{ Heterogeneity } \\
\hline & & & & $\mathrm{I}^{2}$ & $\mathrm{P}$ value \\
\hline \multicolumn{6}{|l|}{ Overall survival } \\
\hline Sample size & 27 & $1.49(1.23,1.82)$ & $<0.0001$ & $85 \%$ & $<0.00001$ \\
\hline$\leq 200$ patients & 10 & $1.64(1.13,2.39)$ & 0.009 & $74 \%$ & $<0.0001$ \\
\hline$>200$ patients & 17 & $1.42(1.16,1.74)$ & 0.0008 & $79 \%$ & $<0.00001$ \\
\hline PLR cut-off & 27 & $1.49(1.23,1.82)$ & $<0.0001$ & $85 \%$ & $<0.00001$ \\
\hline$<200$ & 16 & $1.52(1.15,2.01)$ & 0.004 & $85 \%$ & $<0.00001$ \\
\hline$\geq 200$ & 11 & $1.46(1.09,1.95)$ & 0.01 & $74 \%$ & $<0.0001$ \\
\hline Study location & 27 & $1.49(1.23,1.82)$ & $<0.0001$ & $85 \%$ & $<0.00001$ \\
\hline Asia & 20 & $1.44(1.15,1.80)$ & 0.002 & $64 \%$ & $<0.0001$ \\
\hline Europe & 7 & $1.63(1.11,2.41)$ & 0.01 & $92 \%$ & $<0.00001$ \\
\hline $\begin{array}{l}\text { The cut-off year for the } \\
\text { study }\end{array}$ & 27 & $1.49(1.23,1.82)$ & $<0.0001$ & $85 \%$ & $<0.00001$ \\
\hline $1998 \sim 2010$ & 10 & $1.85(1.40,2.44)$ & $<0.0001$ & $75 \%$ & $<0.0001$ \\
\hline $2011 \sim 2016$ & 17 & $1.29(1.02,1.63)$ & 0.04 & $74 \%$ & $<0.00001$ \\
\hline Published year & 27 & $1.49(1.23,1.82)$ & $<0.0001$ & $85 \%$ & $<0.00001$ \\
\hline $2011 \sim 2016$ & 12 & $1.71(1.44,2.04)$ & $<0.00001$ & $21 \%$ & 0.23 \\
\hline $2017 \sim 2019$ & 15 & $1.39(1.07,1.81)$ & 0.01 & $85 \%$ & $<0.00001$ \\
\hline Median age & 22 & $1.47(1.18,1.82)$ & 0.0005 & $85 \%$ & $<0.00001$ \\
\hline$<50$ & 6 & $1.85(1.34,2.57)$ & 0.0002 & $15 \%$ & 0.32 \\
\hline$\geq 50$ & 16 & $1.38(1.09,1.76)$ & 0.008 & $88 \%$ & $<0.00001$ \\
\hline \multicolumn{6}{|l|}{ Progression-free survival } \\
\hline Sample size & 16 & $1.63(1.30,2.05)$ & $<0.0001$ & $81 \%$ & $<0.00001$ \\
\hline$\leq 200$ patients & 7 & $1.95(1.54,2.48)$ & $<0.00001$ & $0 \%$ & 0.57 \\
\hline$>200$ patients & 9 & $1.41(1.09,1.82)$ & 0.008 & $81 \%$ & $<0.00001$ \\
\hline PLR cut-off & 16 & $1.63(1.30,2.05)$ & $<0.0001$ & $81 \%$ & $<0.00001$ \\
\hline$<200$ & 11 & $1.46(1.14,1.85)$ & 0.002 & $73 \%$ & $<0.00001$ \\
\hline$\geq 200$ & 5 & $1.91(1.55,2.35)$ & $<0.00001$ & $0 \%$ & 0.65 \\
\hline Study location & 16 & $1.63(1.30,2.05)$ & $<0.0001$ & $81 \%$ & $<0.00001$ \\
\hline Asia & 13 & $1.82(1.55,2.14)$ & $<0.00001$ & $7 \%$ & 0.38 \\
\hline Europe & 3 & $1.07(0.89,1.27)$ & 0.48 & $51 \%$ & 0.13 \\
\hline $\begin{array}{l}\text { The cut-off year for the } \\
\text { study }\end{array}$ & 15 & $1.63(1.30,2.05)$ & $<0.0001$ & $81 \%$ & $<0.00001$ \\
\hline 2009 2012 & 6 & $1.80(1.51,2.15)$ & $<0.00001$ & $0 \%$ & 0.82 \\
\hline $2013 \sim 2016$ & 9 & $1.47(1.11,1.93)$ & 0.007 & $71 \%$ & 0.0002 \\
\hline Published year & 16 & $1.63(1.30,2.05)$ & $<0.0001$ & $81 \%$ & $<0.00001$ \\
\hline $2011 \sim 2016$ & 9 & $1.68(1.43,1.98)$ & $<0.00001$ & $0 \%$ & 0.47 \\
\hline 2017 2019 & 7 & $1.56(1.12,2.18)$ & 0.009 & $80 \%$ & $<0.0001$ \\
\hline Median age & 12 & $1.58(1.22,2.06)$ & 0.0006 & $81 \%$ & $<0.00001$ \\
\hline$<50$ & 3 & $1.81(0.81,4.07)$ & 0.15 & $70 \%$ & 0.04 \\
\hline$\geq 50$ & 9 & $1.54(1.16,2.05)$ & 0.003 & $82 \%$ & $<0.00001$ \\
\hline
\end{tabular}

$\mathrm{P}$ values $<0.05$ are in bold.

Table 3.

Subgroup analyses of main outcome for cervical and ovarian cancer 


\begin{tabular}{|c|c|c|c|c|c|}
\hline \multicolumn{6}{|l|}{ Overall survival } \\
\hline \multicolumn{6}{|l|}{ Cervical Cancer } \\
\hline Sample size & 15 & $1.48(1.08,2.04)$ & 0.02 & $71 \%$ & $<0.00001$ \\
\hline$\leq 200$ patients & 6 & $1.47(0.47,2.94)$ & 0.27 & $85 \%$ & $<0.00001$ \\
\hline$>200$ patients & 9 & $1.52(1.23,2.05)$ & 0.006 & $41 \%$ & 0.09 \\
\hline PLR cut-off & 15 & $1.70(1.46,1.99)$ & $<0.00001$ & $71 \%$ & $<0.00001$ \\
\hline$<200$ & 12 & $1.89(1.60,2.25)$ & $<0.00001$ & $57 \%$ & 0.007 \\
\hline$\geq 200$ & 3 & $0.94(0.63,1.40)$ & 0.77 & $85 \%$ & 0.001 \\
\hline The cut-off year for the study & 15 & $1.48(1.08,2.04)$ & 0.02 & $71 \%$ & $<0.00001$ \\
\hline $1998 \sim 2010$ & 4 & $2.60(2.05,3.29)$ & $<0.00001$ & $0 \%$ & 0.59 \\
\hline $2011 \sim 2016$ & 11 & $1.18(0.82,1.69)$ & 0.37 & $59 \%$ & 0.006 \\
\hline Published year & 15 & $1.48(1.08,2.04)$ & 0.02 & $71 \%$ & $<0.00001$ \\
\hline $2011 \sim 2016$ & 5 & $1.56(1.20,2.03)$ & 0.0010 & $3 \%$ & 0.39 \\
\hline $2017 \sim 2019$ & 10 & $1.35(0.83,2.20)$ & 0.22 & $80 \%$ & $<0.00001$ \\
\hline \multicolumn{6}{|l|}{ Ovarian Cancer } \\
\hline Sample size & 8 & $1.51(1.16,1.96)$ & 0.002 & $88 \%$ & $<0.00001$ \\
\hline$\leq 200$ patients & 3 & $1.91(1.47,2.49)$ & $<0.00001$ & $0 \%$ & 0.50 \\
\hline$>200$ patients & 5 & $1.36(1.03,1.80)$ & 0.03 & $88 \%$ & $<0.00001$ \\
\hline PLR cut-off & 8 & $1.51(1.16,1.96)$ & 0.002 & $88 \%$ & $<0.00001$ \\
\hline$<200$ & 3 & $1.33(0.90,1.97)$ & 0.15 & $86 \%$ & 0.0009 \\
\hline$\geq 200$ & 5 & $1.64(1.17,2.32)$ & 0.005 & $77 \%$ & 0.002 \\
\hline The cut-off year for the study & 8 & $1.51(1.16,1.96)$ & 0.002 & $88 \%$ & $<0.00001$ \\
\hline $1998 \sim 2010$ & 4 & $1.53(1.04,2.25)$ & 0.03 & $77 \%$ & 0.005 \\
\hline $2011 \sim 2016$ & 4 & $1.51(1.00,2.28)$ & 0.05 & $90 \%$ & $<0.00001$ \\
\hline Published year & 8 & $1.51(1.16,1.96)$ & 0.002 & $88 \%$ & $<0.00001$ \\
\hline $2011 \sim 2016$ & 4 & $1.97(1.60,2.43)$ & $<0.00001$ & $0 \%$ & 0.56 \\
\hline $2017 \sim 2019$ & 4 & $1.22(0.97,1.54)$ & 0.09 & $80 \%$ & 0.002 \\
\hline
\end{tabular}

\section{Progression-free survival}

\section{Cervical Cancer}

Sample size

$\leq 200$ patients

$>200$ patients

The cut-off year for the study

2009 2012

2013 2016

Published year

$$
\text { 2011 2016 }
$$

2017 2019

\section{Ovarian Cancer}

Sample size

$\leq 200$ patients

$>200$ patients

The cut-off year for the study

$$
\text { 2009 2012 }
$$

2013 2016

Published year

2011 2016

2017 2019

8

3

5

8

2

6

8

4

4

6

3

3

6

3

3

6

4

2
$1.68(1.21,2.33)$

$2.17(1.35,3.47)$

$1.49(0.99,2.24)$

$1.68(1.21,2.33)$

$1.85(1.19,2.87)$

$1.63(1.03,2.56)$

$1.68(1.21,2.33)$

$1.43(1.05,1.95)$

$2.04(1.08,3.88)$

\subsection{2}

0.001

0.06

0.002

0.006

0.04

0.002

0.02

0.03

$1.49(1.08,2.07)$

$1.80(1.33,2.43)$

$1.31(0.90,1.91)$

$1.49(1.08,2.07)$

$1.84(1.48,2.29)$

$1.15(0.85,1.56)$

$1.49(1.08,2.07)$

$1.87(1.51,2.32)$

$1.09(0.86,1.38)$

\begin{tabular}{lll}
0.02 & $87 \%$ & $<0.00001$ \\
0.0002 & $0 \%$ & 0.40 \\
0.15 & $91 \%$ & $<0.0001$ \\
0.02 & $87 \%$ & $<0.00001$ \\
$<0.00001$ & $0 \%$ & 0.73 \\
0.35 & $74 \%$ & 0.02 \\
0.02 & $87 \%$ & $<0.00001$ \\
$<0.00001$ & $0 \%$ & 0.58 \\
0.49 & $76 \%$ & 0.04 \\
\hline
\end{tabular}


$P$ values $<0.05$ are in bold.

\section{Figures}

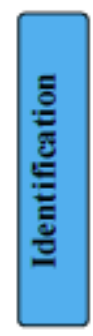

Records identified through database searching $(n=556)$
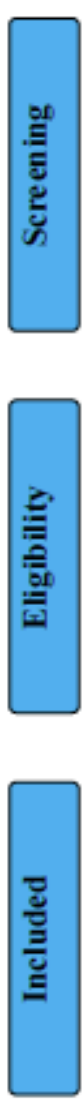

\section{Additional records identified} through other sources $(n=0)$

Records excluded after reading the title and/or abstract $(n=83)$

\section{All full-text articles excluded} $(n=55):$

- Review(n=8)

- Non-English language $(n=2)$

- Conference summaries/abstract only $(n=13)$

- No numerical value for hazard ratio(HR) provided(n=31)

- No identified gynecologic tumor type provided $(n=1)$

\section{Figure 1}

Flow diagram of study selection 
Figure 2A

\begin{tabular}{|c|c|c|c|}
\hline thatyer sump & Inegledarard Batals & & \\
\hline Noyoma 2019 & 0.0242 & 059818974 & $19 \mathrm{~N}$ \\
\hline Aatar 2011 & 0.5308 & 0.25460629 & $4.3 \mathrm{x}$ \\
\hline Badora-Ryotcka 2017 & -0.0101 & 0.50525623 & $6.1 \mathrm{~N}$ \\
\hline Chen 2016 & 0.798 & 0.29989417 & $39 x$ \\
\hline Cummings 2016 & 0.6368 & 0.1911318 & $6.0 \mathrm{~N}$ \\
\hline Farde 2018 & 0.2846 & 0.15067484 & $5.3 \%$ \\
\hline Herage 2516 (1) & 0.9783 & 0.65203613 & $1.7 \mathrm{~N}$ \\
\hline Hnosgs $2016(2)$ & 0.491 & 0.39506732 & $3.1 \%$ \\
\hline Hanma 2015 & -0.6051 & 0.53311395 & $2.2 \mathrm{~N}$ \\
\hline He 2018 & 0.0578 & 0.29011462 & $4.0 \%$ \\
\hline Hohb 2018 & 0.8416 & 0.33144974 & $3.6 \mathrm{~N}$ \\
\hline Huang 2019 & 0.0221 & 0.31017080 & $30 \mathrm{k}$ \\
\hline Ide 2018 & -2.2021 & 0.42816148 & $2.9 \%$ \\
\hline Janska smprok 2018 & 1.0362 & 0.15861905 & $5.3 \mathrm{~N}$ \\
\hline Li2015 & .0 .007 & 0.62123042 & $1.8 \%$ \\
\hline บ 2017 & 0.0971 & 0.10305677 & $0.7 \mathrm{~N}$ \\
\hline Lis 2017 & 0.6528 & 0.23698767 & $4.5 \times$ \\
\hline $\operatorname{Mas} 2015$ & 0.7747 & 0.16600165 & $5.2 \mathrm{~N}$ \\
\hline Nekemara 2019 & -0.6255 & 0.3200062 & $3.7 \%$ \\
\hline Nustpranool 2018 & 0.6931 & 0.70729904 & $1.5 \mathrm{~N}$ \\
\hline Ond 2016 & 0.0751 & $02650 \times 361$ & $43 x$ \\
\hline Roumghaenmanee 2012 & 0.3435 & 0.30547245 & $3.9 \mathrm{x}$ \\
\hline Wang 2017 & $-0,8769$ & 0.83370347 & $19 x$ \\
\hline Zheng 2015 & 0.7692 & 0.19546583 & $49 x$ \\
\hline Zheng 2017 & 0.8547 & 0.78195851 & $3.1 \%$ \\
\hline Zleng 2016 & 0.4344 & 0.20846727 & $4.8 N$ \\
\hline thu 2018 & 10029 & 0.62807964 & $1.0 \%$ \\
\hline
\end{tabular}

Hezard Rato

2.29 10.79, 7.36

$70[1.09,2.60$

$2.990 .99,0.99]$

$169[1.30,2.75$

$1,44[1.07,1.80]$

2.66 p $0.74,9.59$

E) pors, 3.54

56 10.19, 1.55

$32[1.21,4.44]$

$380.75,250]$

$0.62[0.35,1.83]$

$2.96[2.17,4.04]$

$0.2010 .28,3.5$

$120[121,300$

$1711.57,3.00$

$0.410 .23,0.52 \mid$

0.50 p0.13, 2.09

$10010.65,1.600$

14. $12.7,2.57$

$16[1.47,3.17]$

(1) 1121,5 (ख)

$1.54[1.03,2.32]$

$2.6010 .00,9.00]$

$1.49[1.23,1.82]$

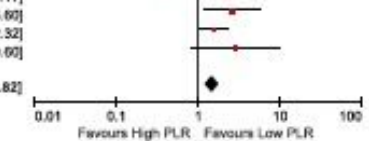

Figure 2B

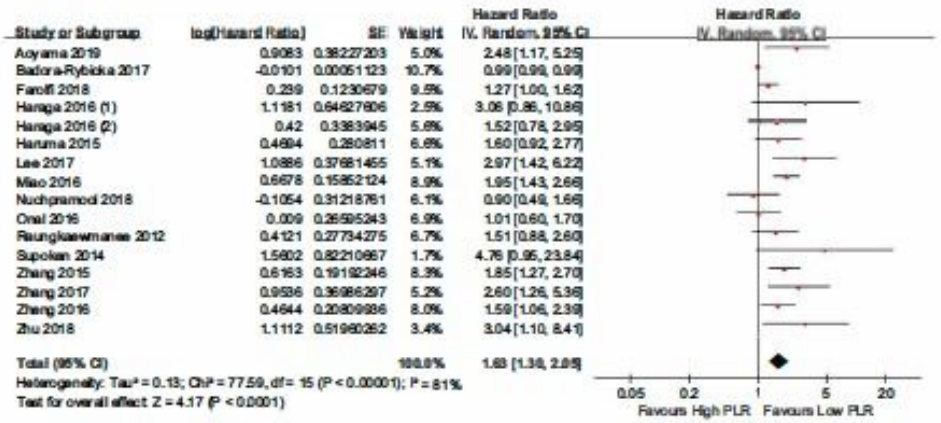

\section{Figure 2}

$2 A \& 2 B$. Forest plots showing hazard ratio for overall survival $(A)$ and progression-free survival $(B)$ in all studies for platelet-to-lymphocyte ratio greater or less than the cut-off. Hazard ratio for each study are represented by the squares, the size of the square represents the weight of the study in the meta-analysis, and the horizontal line crossing the square represents the $95 \%$ confidence interval $(\mathrm{Cl})$. All statistical tests were two-sided. 
Figure 3B

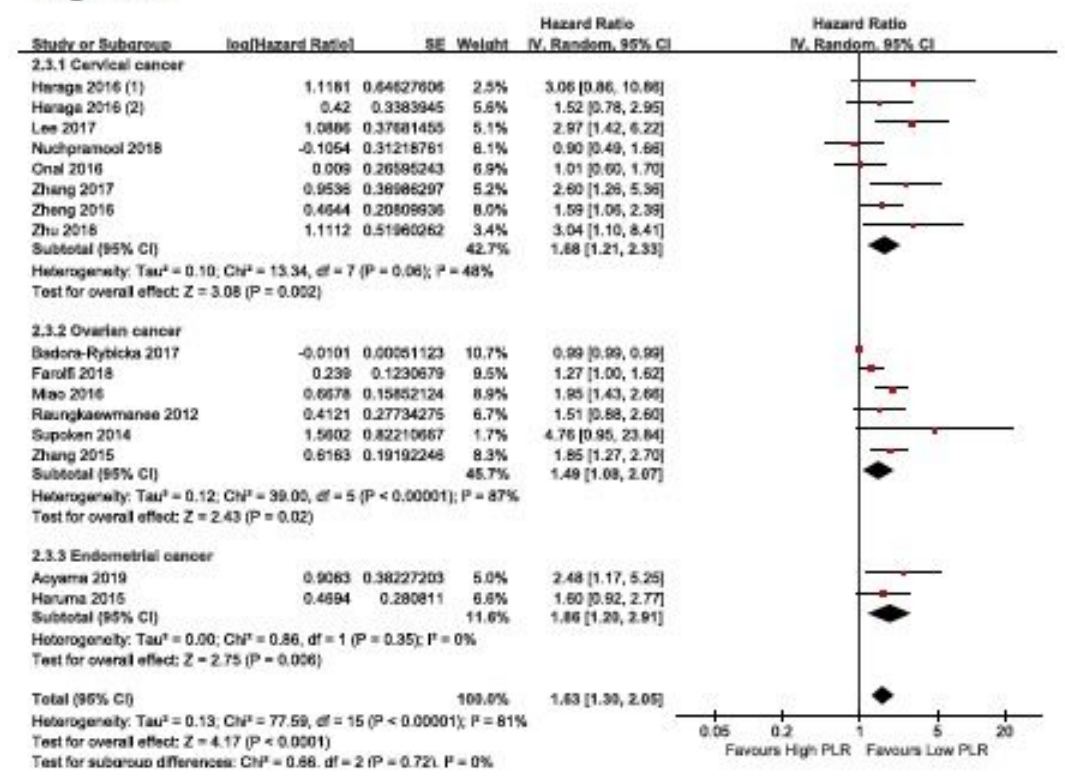

Figure 3A

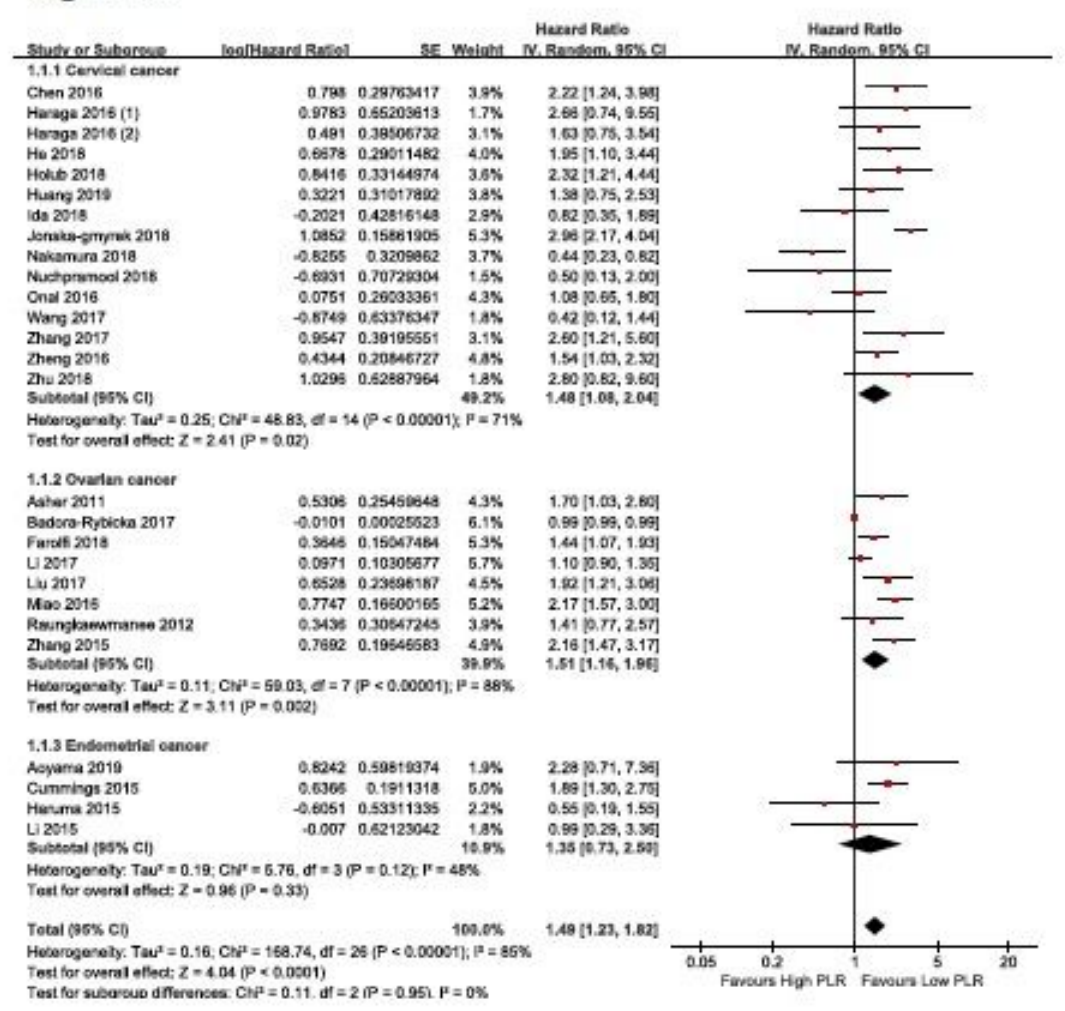

\section{Figure 3}

3A \& 3B. Forest plots showing hazard ratio for overall survival (A) and progression-free survival (B) by primary tumor for platelet-to-lymphocyte ratio greater or less than the cut-off. Hazard ratio for each study are represented by the squares, the size of the square represents the weight of the study in the metaanalysis, and the horizontal line crossing the square represents the $95 \%$ confidence interval $(\mathrm{Cl})$. $\mathrm{All}$ statistical tests were two-sided. 
Figure 4A

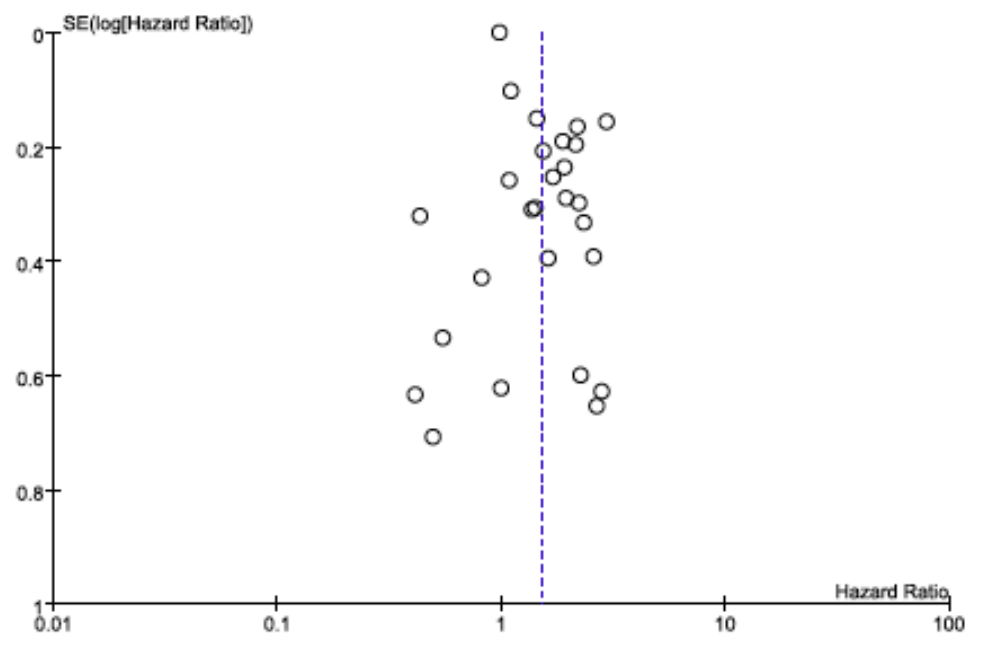

Figure 4B

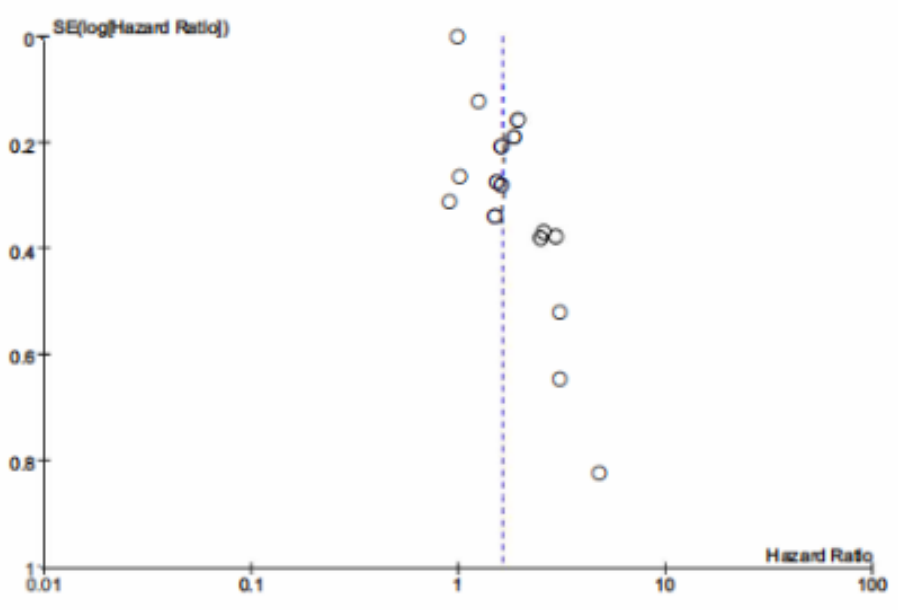

\section{Figure 4}

Funnel plot of hazard ratio for overall survival $(A)$ and progression-free survival (B) for high platelet-tolymphocyte ratio (horizontal axis) and the standard error (SE) for the hazard ratio (vertical axis). Each study is represented by one circle. The vertical line represents the pooled effect estimate. 